\title{
First report of Alternaria alternata causing peanut grey blight in China
}

\author{
Xia Zhang ${ }^{1} \cdot$ Manlin $\mathrm{Xu}^{1} \cdot$ Jing $\mathrm{Yu}^{1}$ - Juxiang $\mathrm{Wu}^{1} \cdot$ Zhiqing Guo $^{1} \cdot$ Yucheng $\mathrm{Chi}^{1}{ }^{10}$
}

Received: 27 February 2020 / Accepted: 22 January 2021 / Published online: 15 February 2021

(c) Società Italiana di Patologia Vegetale (S.I.Pa.V.) 2021

Keywords Peanut grey blight $\cdot$ Alternaria alternata $\cdot$ Molecular identification

In 2018, a previously uncharacterized disease was observed on peanut (Arachis hypogaea) in Qingdao city of China. Symptoms often occured at the tip or margin of the leaves, and the lesions were light brown to dark brown, with wheel pattern of different thicknesses and more intensive. Disease incidence was about 5\% in the area we investigated. There was usually a clear yellow halo at the edge of necrotic tissue. Diseased leaves $\left(25 \mathrm{~mm}^{2}\right)$ were surface disinfested in $1 \%$ $\mathrm{NaOCl}$ for $2 \mathrm{~min}$, rinsed in sterile distilled water, placed on potato dextrose agar (PDA) and incubated at $25{ }^{\circ} \mathrm{C}$ in the dark for 5-7 days. Fungal colonies were initially white, becoming olivaceous, and turning brown with age. Conidia (22.5-40.0 $\times 8.0-13.5 \mu \mathrm{m}$ in size) were obclavate, obpyriform or ellipsoidal with 3 to 5 transverse septa and 1 to 4 longitudinal septa. According to the symptoms and morphological characteristics, the pathogen was tentatively identified as Alternaria alternata (Simmons 2007).

Molecular identification was performed by sequencing four gene regions of a representative isolate ZHX2. The genes were tefl, Alt a 1, gapdh and OPA10-2 (Accession Nos. MN268736, MT559263, MN559264, MW295980), which showed $100 \%, 100 \%, 99.48 \%$ and $98.74 \%$ sequence identity to A. alternata CBS 916.96 from GenBank (KC584634, AY563301, AY278808, KP124632), respectively (Woudenberg et al. 2015). Phylogenetic analysis was done using Neighbor-Joining (NJ) analysis based on those gene sequences. The isolate was identified as A. alternata based on molecular analysis and morphological characteristics.

Four peanut seedlings were spray-inoculated with conidia suspension $\left(1.0 \times 10^{6}\right.$ conidia per $\left.\mathrm{mL}\right)$, and sterile distilled water was used as control (three replicates) in a growth chamber (light culture at $30{ }^{\circ} \mathrm{C}$ for $12 \mathrm{~h}$ and dark culture at $25^{\circ} \mathrm{C}$ for $\left.12 \mathrm{~h}, 80 \% \mathrm{RH}\right)$. Symptoms appeared on leaves 14 days after inoculation, and the lesions were brown, whorled, with yellow halo, while no symptoms appeared on the control. A. alternata was consistently re-isolated from symptomatic tissue, fulfilling Koch's postulates. To our knowledge this is the first report of A. alternata on peanut in China.

\section{References}

Simmons EG (2007) Alternaria: An identification manual. The Netherlands, Utrecht

Woudenberg JHC, Seidl MF et al (2015) Alternaria section Alternaria: Species, formae speciales or pathotypes? Stud Mycol 82:1-21. https://doi.org/10.1016/j.simyco.2015.07.001

Publisher's Note Springer Nature remains neutral with regard to jurisdictional claims in published maps and institutional affiliations.

Xia Zhang and Manlin Xu contributed equally to this work.

Zhiqing Guo

zhiqingivy2011@hotmail.com

Yucheng Chi

87626681@163.com

1 Shandong Peanut Research Institute, Qingdao, Shandong,

China 